\title{
Easy synthesis of graphitic carbon nanocoils from saccharides
}

\author{
Marta Sevilla and Antonio B. Fuertes* \\ Instituto Nacional del Carbón (CSIC), P. O. Box 73, 33080-Oviedo, Spain \\ E-mail: abefu@incar.csic.es, Phone: +34 9851189 70, Fax: +34 985297662
}

\begin{abstract}
Graphitic carbon nanocoils with a high degree of crystallinity have been synthesized by using as intermediates hydrothermally carbonized samples (here denoted as hydrochar) obtained from three representative saccharides (glucose, sucrose and starch). The hydrochar samples were converted to graphitic nanocoils at moderate temperatures $\left(900^{\circ} \mathrm{C}\right)$ using nickel nanoparticles as a graphitization catalyst. The synthesis method involves two simple steps: a) pyrolysis of the Ni impregnated samples at $900^{\circ} \mathrm{C}$ and $\mathrm{b}$ ) liquid-phase oxidation to remove the metallic particles and the non-graphitized (amorphous) carbon. This synthesis scheme allows the fabrication of uniform nanostructures of graphitic nanocoils, with a high level of crystallinity as was demonstrated by different techniques (HRTEM, SAED, XRD and Raman spectroscopy).
\end{abstract}

Keywords: nanostructures, heat treatment. 


\section{Introduction}

Since the discovery of carbon nanotubes by Iijima [1], much attention has been paid to the design of nanostructured carbon materials with graphitic framework structures. As a result a wide variety of structures including nanotubes [1, 2], nanofibers [2, 3], nanocapsules [4, 5], nanocoils [6-9], nanoballs [10], onions [11] nanocones [12] and single-wall nanohorns [13], have been developed. The unique chemical and physical properties of these carbon materials make them suitable for a wide range of applications such as the storage and production of energy [3, 7], as electron field emitters [14], catalyst supports [2], nanocomposites [15] and even for drug delivery [16].

The conventional methods of synthesis used to produce nanostructured carbon materials include laser vaporization [17], plasma and thermally enhanced chemical vapour deposition (CVD) [12] and arc discharge [11]. However, these methods require very high temperatures (arc discharge: $5000-20000^{\circ} \mathrm{C}$, laser vaporization: 4000 $5000^{\circ} \mathrm{C}$ ), which makes them costly and complex in terms of scalability. There is therefore growing interest in the development of low-cost and simple synthesis processes. To this end, the use of certain transition metals or their inorganic compounds to promote graphitization at lower temperatures represents an attractive alternative. This process, which is known as catalytic graphitization, has already been extensively studied [18, 19]. Its main advantage is that both graphitizing and non-graphitizing carbons can be transformed into crystalline materials at relatively low temperatures $(\mathrm{T}<$ $1000^{\circ} \mathrm{C}$ ), whereas uncatalysed graphitization requires the use of temperatures greater than $2000-2500^{\circ} \mathrm{C}$ and carbon precursors that have graphitizable properties. We have previously investigated the catalytic graphitization of several low-cost and widely available carbon precursors, such as sawdust [20] and saccharides [21]. In the course of our investigation a variety of graphitic carbon nanostructures, sometimes coexisting in 
the same sample (i.e. nanocapsules, nanoribbons, bamboo-like nanopipes and nanocoils), were synthesized. Amorphous carbon microcoils/nanocoils have been previously synthesized by the catalytic chemical vapor deposition of acetylene [6-9, 22]. However, to the best of our knowledge, the low-temperature synthesis of graphitic carbon nanoparticles with a coil morphology has not yet been reported. In this work, we present a novel and easy synthesis route to obtain graphitic carbon nanocoils at a moderate temperature $\left(900^{\circ} \mathrm{C}\right)$. The methodology is based on using as carbon precursors hydrochar microspheres obtained by the hydrothermal carbonization of saccharides with nickel as the graphitization catalyst. Our hypothesis is that the hydrochar microspheres constitute a suitable carbon precursor if one takes into account the high concentration of surface oxygen functional groups $(>\mathrm{C}=\mathrm{O},-\mathrm{OH},-\mathrm{COOH}$, etc) [23], which will favor the dispersion of the nickel catalyst when this is incorporated into the carbonaceous microspheres. The dispersion of the nickel catalyst is important for obtaining high graphitic carbon yields and uniform carbon nanostructures.

In relation to the potential applications of the carbon nanocoils fabricated according to the procedure here presented, it is worth noting that in a previous work we demonstrated that these graphitic nanostructures constitute excellent supports for PtRu nanoparticles for methanol electrooxidation, exceeding the performance of the electrocatalyst prepared with the commonly used carbon support Vulcan XC-72R [24]. Whereas the preceding work was focused on the employ of the carbon nanocoils as electrocatalyst supports, here we examine in detail the synthetic route used to prepare these nanostructures from different types of saccharides and their structural properties. 


\section{Experimental}

\subsection{Synthesis of graphitic carbon nanocoils (GCNC)}

As a first step in our synthesis scheme, hydrochar microspheres were prepared by a hydrothermal method as reported previously [23], using three representative saccharides: $\alpha$-D-Glucose (96\%, Aldrich), D(+)-sucrose (Rectapur, Prolabo) and potato starch (Sigma-Aldrich). Briefly, an aqueous saccharide solution (1 M for glucose, $0.5 \mathrm{M}$ for sucrose and $0.25 \mathrm{M}$ for starch) was placed in a Teflon-lined autoclave and maintained at a preselected temperature $\left(240^{\circ} \mathrm{C}\right.$ for glucose, $190^{\circ} \mathrm{C}$ for sucrose, and 180 $200^{\circ} \mathrm{C}$ for starch) for a certain period of time $(0.5$ and $1 \mathrm{~h}$ for glucose, $4.5 \mathrm{~h}$ for sucrose and starch). The solid products obtained consisted of hydrochar spherules, which were retrieved by centrifugation.

The hydrochar samples were catalytically graphitized using nickel as catalyst. The as-made powder was impregnated with a solution of nickel nitrate in ethanol (2 mmol $\left.\mathrm{Ni} \cdot \mathrm{g}^{-1} \mathrm{C}\right)$ and then heat-treated under $\mathrm{N}_{2}$ at $900^{\circ} \mathrm{C}\left(3^{\circ} \mathrm{C} \cdot \mathrm{min}^{-1}, 3 \mathrm{~h}\right)$. Finally, the material was washed with $20 \% \mathrm{HCl}$ in order to remove the metal particles and dried at $120^{\circ} \mathrm{C}$. The carbon samples thus obtained consisted of a mixture of amorphous carbon and graphitic nanostructures. In order to extract pure GCNC, the graphitized material was oxidized (under reflux for $2 \mathrm{~h}$ ) in an acid solution of potassium permanganate with a composition (molar ratio) of $\mathrm{H}_{2} \mathrm{O} / \mathrm{H}_{2} \mathrm{SO}_{4} / \mathrm{KMnO}_{4}=1: 0.02: 0.006$. Typically $180 \mathrm{~mL}$ of

solution was used per $0.8 \mathrm{~g}$ of raw material. The solid residue was separated by centrigufation, treated with $\mathrm{HCl}(10 \mathrm{wt} \%)$ to remove the $\mathrm{MnO}_{2}$, rinsed with abundant distilled water and oven-dried at $120^{\circ} \mathrm{C}$ for $2 \mathrm{~h}$. The samples were labelled as CG1 (glucose, $240^{\circ} \mathrm{C}, 1 \mathrm{M}, 0.5 \mathrm{~h}$ ), CG2 (glucose, $240^{\circ} \mathrm{C}, 1 \mathrm{M}, 1 \mathrm{~h}$ ), CS (sucrose, $190^{\circ} \mathrm{C}$, 0.5M, $4.5 \mathrm{~h}$ ), CA1 (starch, $180^{\circ} \mathrm{C}, 0.25 \mathrm{M}, 4.5 \mathrm{~h}$ ) and CA2 (starch, $200^{\circ} \mathrm{C}, 0.25 \mathrm{M}, 4.5$ h). 


\subsection{Characterization of materials}

Adsorption measurements of the samples were performed using a Micromeritics ASAP 2020 volumetric physisorption system. The BET surface area was deduced by an isotherm analysis in the relative pressure range of 0.04 to 0.20 . The total pore volume was calculated from the amount adsorbed at a relative pressure of 0.99 . The external surface area $\left(\mathrm{S}_{\mathrm{ext}}\right)$ was estimated by means of the $\alpha_{\mathrm{s}}$-plot method and a nongraphitized carbon black was used as a reference [25]. X-ray diffraction (XRD) patterns were obtained on a Siemens D5000 instrument operating at $40 \mathrm{kV}$ and $20 \mathrm{~mA}$, using $\mathrm{CuK} \alpha$ radiation $(\lambda=0.15406 \mathrm{~nm})$. Transmission electron micrographs $($ TEM) were taken on a JEOL (JEM-2000 FX) microscope operating at $200 \mathrm{kV}$. High resolution transmission electron micrographs (HRTEM) were taken on a JEOL (JEM-4000EX) microscope operating at $400 \mathrm{kV}$. The Raman spectra were recorded with a Horiva (LabRam HR800) spectrometer. The radiation source was a laser operating at a wavelength of 514 $\mathrm{nm}$ and a power of $25 \mathrm{~mW}$.

\section{Results and discussion}

In order to investigate the chemical transformations occurring during the heat treatment of the nickel impregnated samples, we examined the changes in structural properties of samples obtained at different temperatures. Thus, Figure 1 shows the XRD spectra for the materials prepared at temperatures in the $300-900^{\circ} \mathrm{C}$ range. The $\mathrm{XRD}$ pattern corresponding to an impregnated sample treated at $300^{\circ} \mathrm{C}$ clearly reveals the presence of $\mathrm{NiO}$ nanoparticles (crystallite size of approx. $2.6 \mathrm{~nm}$ ). The presence of both $\mathrm{NiO}$ and $\mathrm{Ni}$ nanoparticles in the material obtained at $370^{\circ} \mathrm{C}$ indicates the onset of reduction of $\mathrm{NiO}$ at around this temperature. At $700^{\circ} \mathrm{C}$ the $\mathrm{XRD}$ pattern reveals that: a) the nickel oxide has been completely reduced to nickel nanoparticles, which have a diameter of around $17 \mathrm{~nm}, \mathrm{~b}$ ) the graphitization process has not yet begun, as reflected 
by the absence of the XRD peaks characteristic of graphite. Catalytic graphitization seems to begin in the $700-730^{\circ} \mathrm{C}$ range. In fact, the XRD pattern corresponding to a sample prepared at $730^{\circ} \mathrm{C}$ evidences the formation of graphitic carbon, which is confirmed by the appearance of a sharp (002) reflection at $\sim 26^{\circ}$ in the X-ray diffraction pattern. This reflection is superimposed on a broad band, which denotes the presence of a large fraction of amorphous carbon. As the temperature rises from $730^{\circ} \mathrm{C}$ to $900^{\circ} \mathrm{C}$, the intensity of the (002) band increases, while at the same time the broad band corresponding to the amorphous carbon gradually decreases. This indicates that, as the temperature rises, the amount of graphitic carbon generated increases. On the other hand, the structural characteristics of the materials $\left(\mathrm{d}_{002}\right.$ and $\left.\mathrm{L}_{\mathrm{c}}\right)$, deduced from the XRD patterns, hardly change at all, as the temperature rises $\left(\mathrm{d}_{002}=0.341-0.342 \mathrm{~nm}\right.$ and $\mathrm{L}_{\mathrm{c}}=$ 9.0-9.3 nm). This suggests that, while the increase in temperature does not have a marked influence on the degree of structural order of the graphitic carbon generated, it does affect the amount of graphitic structures. As the temperature rises from $700^{\circ} \mathrm{C}$ to $900^{\circ} \mathrm{C}$ the diameter of the nickel nanoparticles widens to around $22 \mathrm{~nm}\left(900^{\circ} \mathrm{C}\right)$, as deduced by applying the Scherrer equation to the Ni (111) reflection.

In order to assess the importance of using the hydrochar as carbon precursor instead of the carbonized material, we compared the structural properties of two samples: a) hydrochar microspheres impregnated with nickel salt and heat-treated to $400^{\circ} \mathrm{C}$ and $\mathrm{b}$ ) carbon microspheres (obtained by the carbonization of hydrochar spherules at $800^{\circ} \mathrm{C}$ for $1 \mathrm{~h}$ ) impregnated with nickel nitrate and heat-treated to $400^{\circ} \mathrm{C}$. Figure 2 shows the TEM images obtained for both materials. It can be seen that, while for the hydrochar sample, the Ni nanoparticles formed have a uniform size $(\sim 14 \pm 2 \mathrm{~nm})$ and are uniformly distributed along the carbon matrix, for the carbonized material the metallic nanoparticles are heterogeneously distributed and display a wide range of sizes with 
diameters reaching in some cases $50 \mathrm{~nm}$. This result demonstrates that hydrochar microspheres favour a good dispersion of the catalyst nanoparticles, probably due to the presence of abundant surface oxygen functional groups, thus confirming our hypothesis.

Catalytic graphitization takes place via the interaction between the nickel nanoparticles and the amorphous carbon surrounding them. During this process, the metallic nanoparticles move through the amorphous carbon, leaving behind a track of graphitic carbon in accordance with a dissolution-precipitation mechanism [18, 19, 26]. This is evidenced by the TEM images shown in Figures 3a and 3b, where the trajectory followed by the $\mathrm{Ni}$ nanoparticles is marked with an arrow. These graphitic nanostructures are immersed in a matrix of amorphous carbon as evidenced by the TEM image in Figure 3c. The amorphous carbon acts as a binder, as a result of which the original spherical morphology of the hydrochar precursor is preserved. This is clear from the SEM image in Figure 3d. The spherules contract only slightly during the carbonization/graphitization process (see Table 1). The oxidation process leads to the dissolution of the amorphous carbon which surrounds the graphitic nanostructures, causing the spherical particles to disintegrate. As a consequence, the carbon material obtained after the oxidation step appears as an aggregate of nanoparticles (see Figure 3e). These nanoparticles have a coil morphology, as can be seen from the TEM images of the samples derived from glucose (Figure 4a), sucrose (Figure 4c) and starch (Figure 4e). The images show that the nanocoils have a diameter of around 70-100 $\mathrm{nm}$ and consist of a long curved ribbon of carbon (several microns in length and $\sim 5 \mathrm{~nm}$ in width). This material has a high crystallinity (graphitic order) as evidenced by the HRTEM images (Figures 4b, 4d and 4f), which display very well-defined (002) lattice fringes, and also by the selected area electron diffraction patterns (as an example, see inset in Figure 4f). The crystallinity of the GCNC was independently confirmed by 
means of X-ray diffraction analysis (Figure 5a) and Raman spectroscopy (Figure 5b). Thus, the XRD patterns exhibit intense XRD peaks at $2 \theta=\sim 26^{\circ}, \sim 43^{\circ}, \sim 54^{\circ}$ y $\sim 78^{\circ}$, which correspond to the (002), (10), (004) y (110) diffractions of the graphitic framework, respectively. The structural properties of the graphitic carbon nanocoils (GCNC) were obtained from an analysis of the XRD patterns. The plane spacing, $\mathrm{d}_{002}$, was deduced by applying Bragg's equation to the (002) diffraction peak, while the crystallite sizes perpendicular to the basal plane, $\mathrm{L}_{\mathrm{c}}$, and parallel to the basal plane, $\mathrm{L}_{\mathrm{a}}$, were deduced by applying Scherrer's equation to the (002) and (110) diffraction peaks, respectively. All the samples possess a similar structural order, the $\mathrm{d}_{002}$ value being $0.342-0.343 \mathrm{~nm}$, and the $\mathrm{L}_{\mathrm{c}}$ and $\mathrm{L}_{\mathrm{a}}$ values being of the order of $8.7-9.4 \mathrm{~nm}$ and $23-$ $27 \mathrm{~nm}$ respectively (see Table 1). The values obtained for $\mathrm{d}_{002}$ are larger than the value corresponding to graphite $(0.335 \mathrm{~nm})$ suggesting that some distortion has occurred in the stacking of the graphene layers (turbostratic order) [27]. In all cases, the size of the graphite microcrystallites along the basal plane is larger than the size of the graphite microcrystallites perpendicular to the basal plane $\left(\mathrm{L}_{\mathrm{a}}>\mathrm{L}_{\mathrm{c}}\right)$, which suggests that the incorporation of new carbon atoms into the already existing graphitic layers is favoured over the formation of new graphitic layers [28]. Typical Raman spectra of the GCNs are shown in Figure 5b. Intense and narrow $\mathrm{G}$ (associated to the $\mathrm{E}_{2} \mathrm{~g}_{2}$ vibrational mode of $\mathrm{sp}^{2}$ bonded carbon atoms $)\left(\sim 1565-1580 \mathrm{~cm}^{-1}\right)$ and $\mathrm{G}^{\prime}\left(\sim 2680-2700 \mathrm{~cm}^{-1}\right)$ bands are observed in the first- and second-order Raman spectra respectively, indicating a high biand tridimensional order [29]. The relatively high intensity of the D band (related to imperfections in the graphitic $\mathrm{sp}^{2}$ carbon structures) $\left(\sim 1342-1353 \mathrm{~cm}^{-1}\right)$, which leads to values of $\mathrm{I}_{\mathrm{D}} / \mathrm{I}_{\mathrm{G}} \sim 1$, can be attributed to the distortion of the GCNs, which affects the degree of crystallite orientation (edge/basal plane proportion) and therefore the Raman 
measurements [30-32]. It is important to emphasize the absence of the D" band at $\sim 1500 \mathrm{~cm}^{-1}$, attributed to the presence of amorphous carbon [33-35].

Representative nitrogen sorption isotherms corresponding to the graphitized samples before and after the removal of amorphous carbon are shown in Figures $6 \mathrm{a}$ and $6 \mathrm{~b}$ respectively. It can be seen that before the amorphous carbon is removed, the material exhibits a type IV isotherm with a $\mathrm{H} 2$ hysteresis loop. This is indicative of the presence of constrictions in the porous network, which are probably associated with disordered carbon. This type of materials has a BET surface area in the $140-180 \mathrm{~m}^{2} \cdot \mathrm{g}^{-1}$ range and a pore volume of around $0.2 \mathrm{~cm}^{3} \cdot \mathrm{g}^{-1}$, which is associated with the framework-confined mesopores. In contrast, the nitrogen sorption isotherm corresponding to the graphitic carbon nanocoils does not present any hysteresis loop and exhibits a large $\mathrm{N}_{2}$ adsorption uptake for $\mathrm{p} / \mathrm{p}_{\mathrm{o}}>0.85$. The shape of this isotherm is typical of nanosized materials with no framework-confined pores. In this case, adsorption takes place on the external surface of the nanostructures, so that the estimated BET surface area can be expected to match the external surface area. Application of the $\alpha_{\mathrm{s}}$-plot analysis to the $\mathrm{N}_{2}$ adsorption branch of the isotherms confirms the above results. Indeed, the $\alpha_{\mathrm{s}}$-plot corresponding to the graphitized sample (before oxidation) (Inset in Figure 6a) shows that the porosity of this material consists partly of micropores (the initial linear section of the plot does not pass through the point of origin) but mainly of framework-confined mesopores (for $\alpha_{\mathrm{s}}>$ 2 there is a plateau in the curve indicating the presence of mesopores). On the other hand, the $\alpha_{\mathrm{s}}$-plot corresponding to the GCNC (Inset in Figure $6 \mathrm{~b}$ ) is typical of a material without micropores or mesopores (the initial linear section of the $\alpha_{\mathrm{s}}$-plot passes through the point of origin). For this type of material, the upward deviation from linearity for $\alpha_{\mathrm{s}}$ $>2$ corresponds to the adsorption by the interparticle voids between the GCNC. The 
initial linear section of the $\alpha_{s}$-plot of the GCNC leads to external surface area values of $121-140 \mathrm{~m}^{2} \cdot \mathrm{g}^{-1}$, which are close to those of the BET surface area $\left(114-134 \mathrm{~m}^{2} \cdot \mathrm{g}^{-1}\right)$.

\section{Conclusions}

In summary, a new and simple procedure for the fabrication of graphitic carbon nanocoils is presented. This synthesis method is based on using as carbon precursor hydrochar microspheres obtained by the hydrothermal carbonization of different saccharides (glucose, sucrose and starch). The formation of the graphitic nanostructures takes place at moderate temperatures $\left(900^{\circ} \mathrm{C}\right)$ with the aid of nickel as graphitization catalyst. The graphitization process begins at $730^{\circ} \mathrm{C}$ and then, as the temperature rises, the proportion of graphitic nanostructures present in the carbonized sample increases. The key to the formation of uniform and abundant graphitic nanostructures is the use of a carbon precursor that contains a large concentration of surface oxygen functionalities, as this will ensure that the catalyst is widely dispersed. The graphitized material consists of a mixture of amorphous and graphitic structures, but pure graphitic carbon nanocoils can be extracted from this mixture by a simple oxidative treatment. These nanostructures have a high degree of crystallinity, as was demonstrated a variety of techniques (TEM, SAED, HRTEM, XRD and Raman spectroscopy).

Acknowledgments. The financial support for this research work provided by the Spanish MCyT (MAT2005-00262) is gratefully acknowledged. M.S. acknowledges the assistance of the Spanish MCyT for the award of a FPU grant. 


\section{References}

[1] S. Iijima, Nature 354 (1991) 56.

[2] P. Serp P, M. Corrias, Kalck P, Appl. Cat. A 253 (2003) 337.

[3] K.P. De Jong, J.W. Geus, Cat. Rev.: Sci. Eng. 42 (2000) 481.

[4] S. Han, Y. Yun, K.-W. Park, Y.-E. Sung, T. Hyeon, Adv. Mater. 15 (2003) 1922.

[5] B.S. Xu, J.J. Guo, X. M. Wang, X.G. Liu, H. Ichinose, Carbon 44 (2006) 2631.

[6] S. Motojima, X. Chen, S. Yang, M. Hasegawa, Diam. Relat. Mater. 13 (2004) 1989.

[7] Y. Liu, Z. Shen, Carbon 43 (2005) 1574.

[8] S. Yang, X. Chen, T. Katsuno, S. Motojima, Mater. Res. Bull. 42 (2007) 465.

[9] T. Hyeon, S. Han, Y.-E. Sung, K.-Y. Park, Y.-W. Kim, Angew. Chemie. Int. Ed. 42 (2003) 4352.

[10] X. He, F. Wu, M. Zheng, Diam. Relat. Mater. 16 (2007) 311.

[11] D. Ugarte, Carbon 33 (1995) 989.

[12] C.K. Tan, K.P. Loh, J.T.L. Thong, C.H. Sow, H. Zhang, Diam. Relat. Mater. 14 (2005) 902.

[13] S. Iijima, M. Yudasaka, R. Yamada, S. Bandow, K. Suenaga, F. Kokai, K. Takahashi, Chem. Phys. Lett. 309 (1999) 165.

[14] Y. Saito, S. Uemura, Carbon 38 (2000)169.

[15] E.T. Thostenson, Z. Ren, T.W. Chou, Compos. Sci. Tech. 61 (2001) 1899.

[16] N. Venkatesan, J. Yoshimitsu, Y. Ito, N. Shibata, K. Takada, Biomaterials 26 (2005) 7154.

[17] T. Guo, P. Nikolaev, A. Thess, D.T. Colbert, R.E. Smalley, Chem. Phys. Lett. 243 (1995) 49.

[18] F.J. Derbyshire, A.E.B. Presland, D.L. Trimm, Carbon 13 (1975) 111.

[19] A. Oya, H. Marsh, J. Mater. Sci. 17 (1982) 309. 
[20] M. Sevilla, C. Sanchís, T. Valdés-Solís, E. Morallón, A.B. Fuertes, J. Phys. Chem. C $111(2007) 9749$.

[21] M. Sevilla, C. Sanchís, T. Valdés-Solís, E. Morallón, A.B. Fuertes. Carbon 46 (2008) 931.

[22] Q. Liu, Z.-M. Cui, Z. Ma, S.-W. Bian, W.-G. Song, Phys. Chem. C 111 (2007) 12420.

[23] M. Sevilla. Nuevos materiales de carbono para el almacenamiento y la producción de energía. University of Oviedo, PhD Thesis, 2008.

[24] M Sevilla, G. Lotta, A.B. Fuertes, J. Power Sources 171 (2007) 546.

[25] M. Kruk, M. Jaroniec, K.P. Gadkaree, J. Colloid. Interface. Sci. 192 (1997) 250.

[26] H. Marsh, D. Crawford, D.W. Taylor DW, Carbon 21 (1983) 81.

[27] M. Inagaki. New carbons. Control of structure and functions. Elsevier, Amsterdam, 2000.

[28] R.E. Franklin, P. Roy. Soc. Lond. A Mat. 209 (1951) 196.

[29] P. Lespade, A. Marchand, M. Couzi, F. Cruege, Carbon 22 (1984) 375.

[30] Y. Wang, D.C. Alsmeyer, R.L. McCreery, Chem. Mater. 2 (1990) 557.

[31] P. Delhaes, M. Couzi, M. Trinquecoste, J. Dentzer, H. Hamidou, C. Vix-Guterl, Carbon 44 (2006) 3005.

[32] L.G. Cançado, M.A. Pimenta, B.R.A. Neves, M.S.S. Dantas, A. Jorio, Phys. Rev. Lett. 93 (2004) 247401.

[33] A. Cuesta, P. Dhamelincourt, J. Laureyns, A. Martínez-Alonso, J.M.D. Tascón, Carbon 32 (1994) 1523.

[34] A. Sadezky, H. Muckenhuber, H. Grothe, R. Niessner, U. Pöschl, Carbon 43 (2005)1731. 
[35] S.E. Hong, D.-K. Kim, S.M. Jo, D.Y. Kim, B.D. Chin, D.W. Lee, Catal. Today 120 (2007) 413. 
Table 1. Synthesis conditions and structural properties of the graphitic carbon nanocoils.

\begin{tabular}{|c|c|c|c|c|c|c|c|c|c|}
\hline \multirow{2}{*}{ Precursor } & \multirow{2}{*}{$\begin{array}{l}\text { Sample } \\
\text { Code }\end{array}$} & \multicolumn{3}{|c|}{ Hydrochar synthesis ${ }^{a}$} & \multicolumn{2}{|c|}{ Spherule size $(\mathrm{nm})^{b}$} & \multicolumn{3}{|c|}{ Structural properties ${ }^{\mathrm{c}}$} \\
\hline & & $\mathrm{C}(\mathrm{M})$ & $\mathrm{T}\left({ }^{\circ} \mathrm{C}\right)$ & $\mathrm{t}(\mathrm{h})$ & $\begin{array}{c}\text { Before } \\
\text { carboniz. }\end{array}$ & $\begin{array}{c}\text { After } \\
\text { carboniz. }\end{array}$ & $\begin{array}{l}\mathrm{d}_{002} \\
(\mathrm{~nm})\end{array}$ & $\begin{array}{c}\mathrm{L}_{\mathrm{c}} \\
(\mathrm{nm})\end{array}$ & $\begin{array}{c}\mathrm{L}_{\mathrm{a}} \\
(\mathrm{nm})\end{array}$ \\
\hline \multirow{2}{*}{ Glucose } & CG1 & 1 & 240 & 0.5 & $1.0( \pm 0.1)$ & $0.80( \pm 0.10)$ & 0.342 & 9.1 & 24 \\
\hline & CG2 & 1 & 240 & 1 & $1.9( \pm 0.2)$ & $1.9( \pm 0.2)$ & 0.344 & 9.3 & 24 \\
\hline \multirow{2}{*}{ Starch } & CA1 & 0.25 & 180 & 4.5 & $1.3( \pm 0.2)$ & $0.90( \pm 0.28)$ & 0.343 & 9.3 & 24 \\
\hline & CA2 & 0.25 & 200 & 4.5 & $1.7( \pm 0.5)$ & $1.3( \pm 0.4)$ & 0.342 & 9.4 & 23 \\
\hline Sucrose & $\mathrm{CS}$ & 0.5 & 190 & 4.5 & $6.0( \pm 2.1)$ & $4.8( \pm 1.5)$ & 0.342 & 8.7 & 21 \\
\hline
\end{tabular}

${ }^{a}$ Conditions used for hydrothermal carbonization: Concentration of saccharide $(\mathrm{C}$ in $\mathrm{mol} / \mathrm{L})$, temperature $(\mathrm{T})$ and reaction time $(\mathrm{t}) ;{ }^{\mathrm{b}}$ mean diameter of hydrochar microspheres. Standard deviation is indicated in parenthesis; ${ }^{\mathrm{c}}$ structural properties of GCNC. 


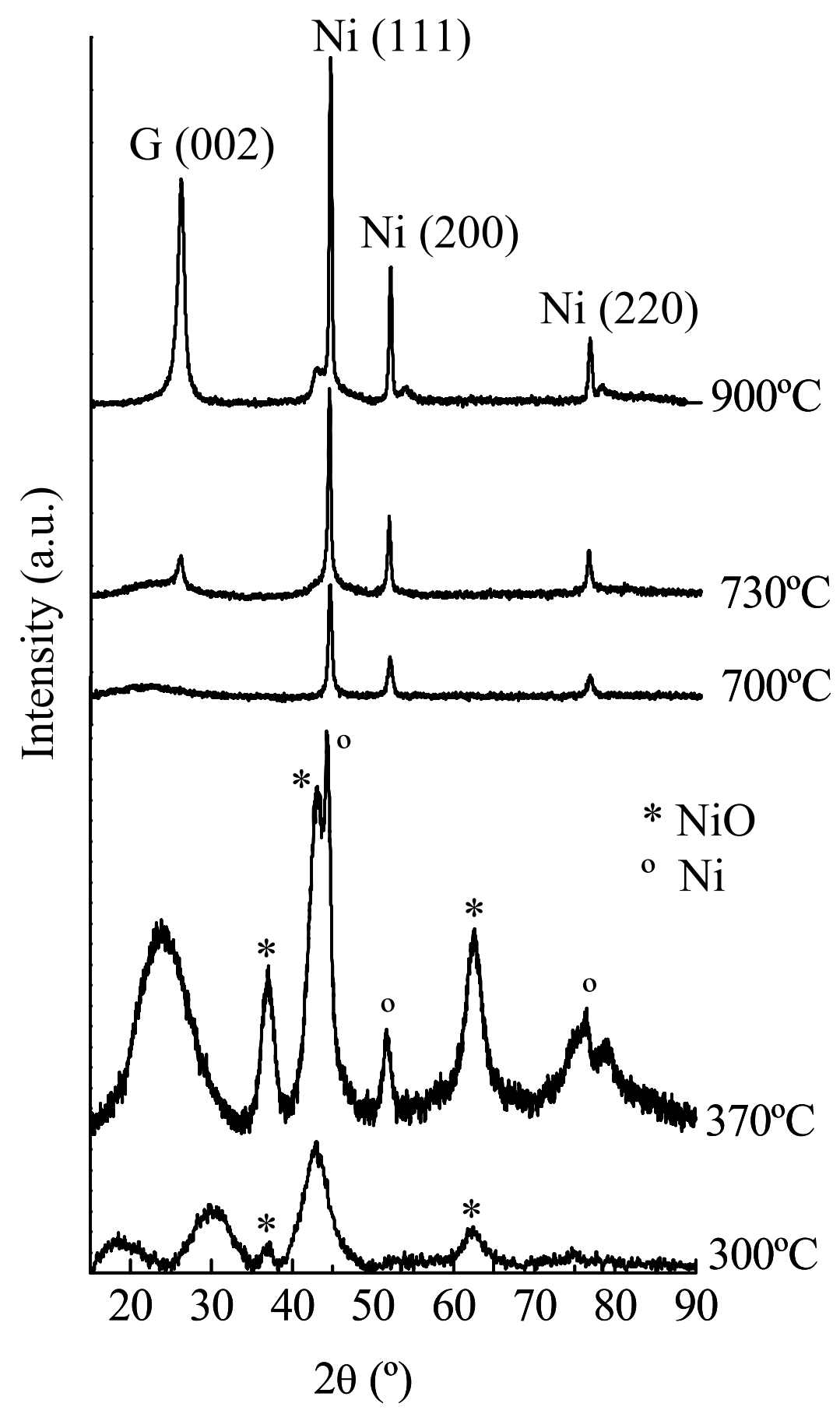

Figure 1. XRD patterns for the materials obtained by the treatment of hydrochar samples (glucose-based) impregnated with nickel nitrate at different temperatures (under an inert atmosphere). 


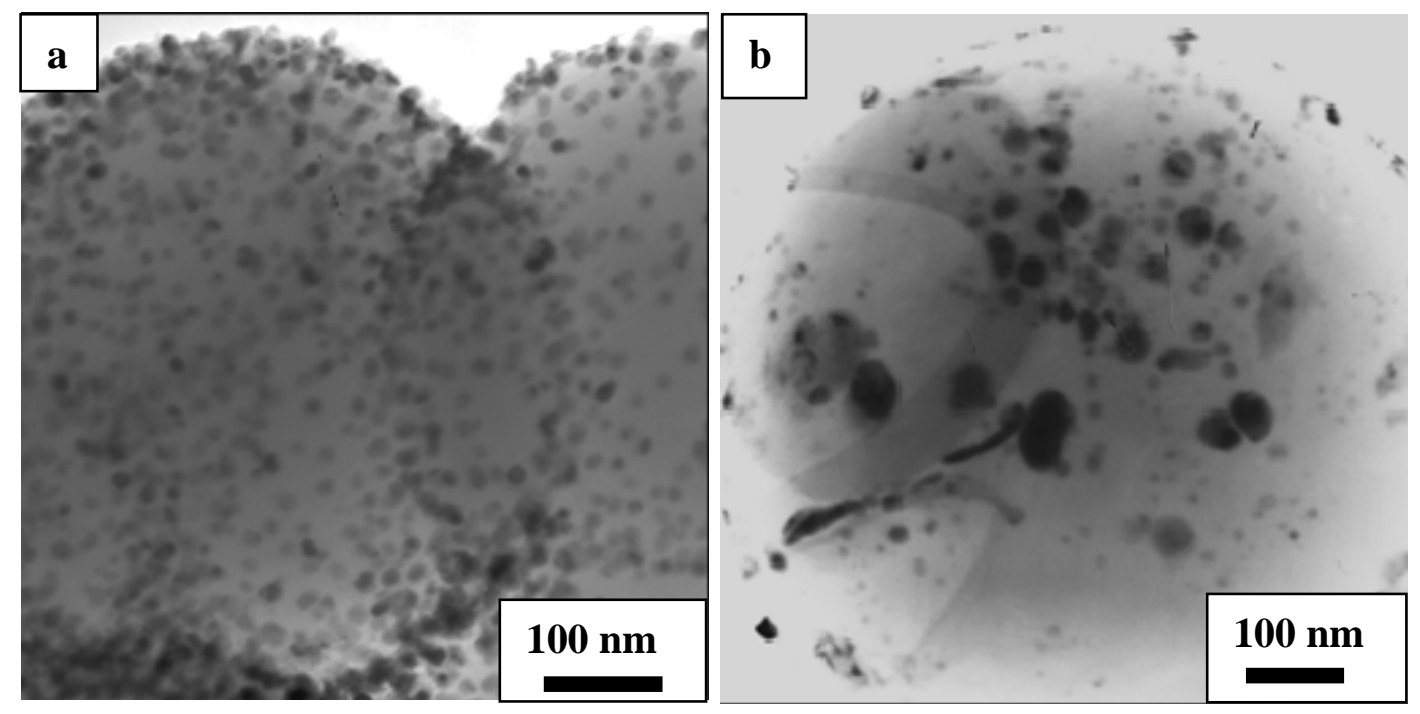

Figure 2. TEM images of hydrochar (a) and carbonized microspheres (b) impregnated with nickel nitrate and heat-treated to $400^{\circ} \mathrm{C}$. 


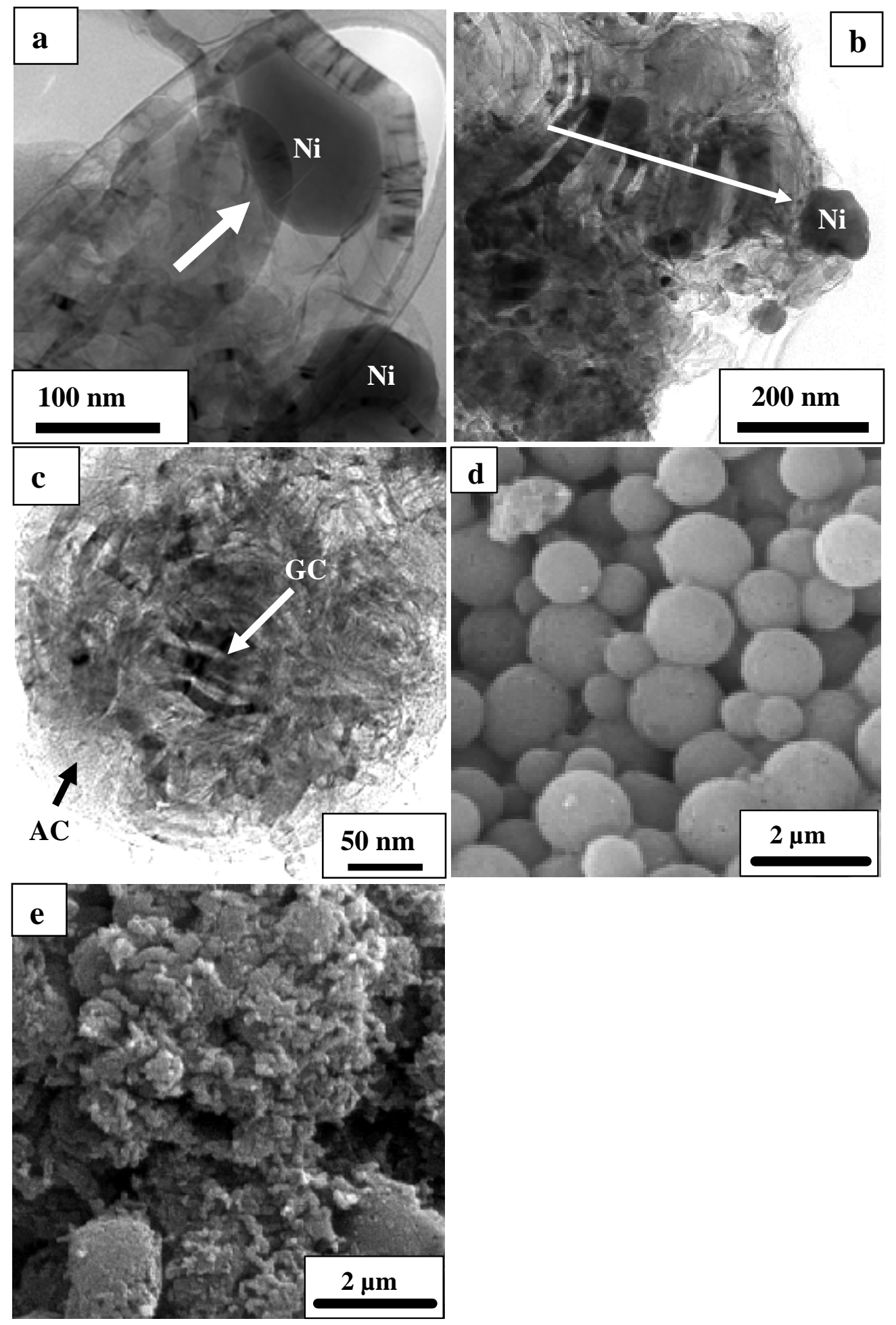

Figure 3. TEM (a, b, c) and SEM (d, e) microphotographs of graphitized (at $900^{\circ} \mathrm{C}$ ) hydrochar samples before (a, b, c and d) and after (e) oxidative treatment. Image (a) is of glucose-based hydrochar and (b, c, d, e) correspond to starch-based hydrochar samples. (AC=amorphous carbon and $\mathrm{GC}=$ graphitic carbon). 

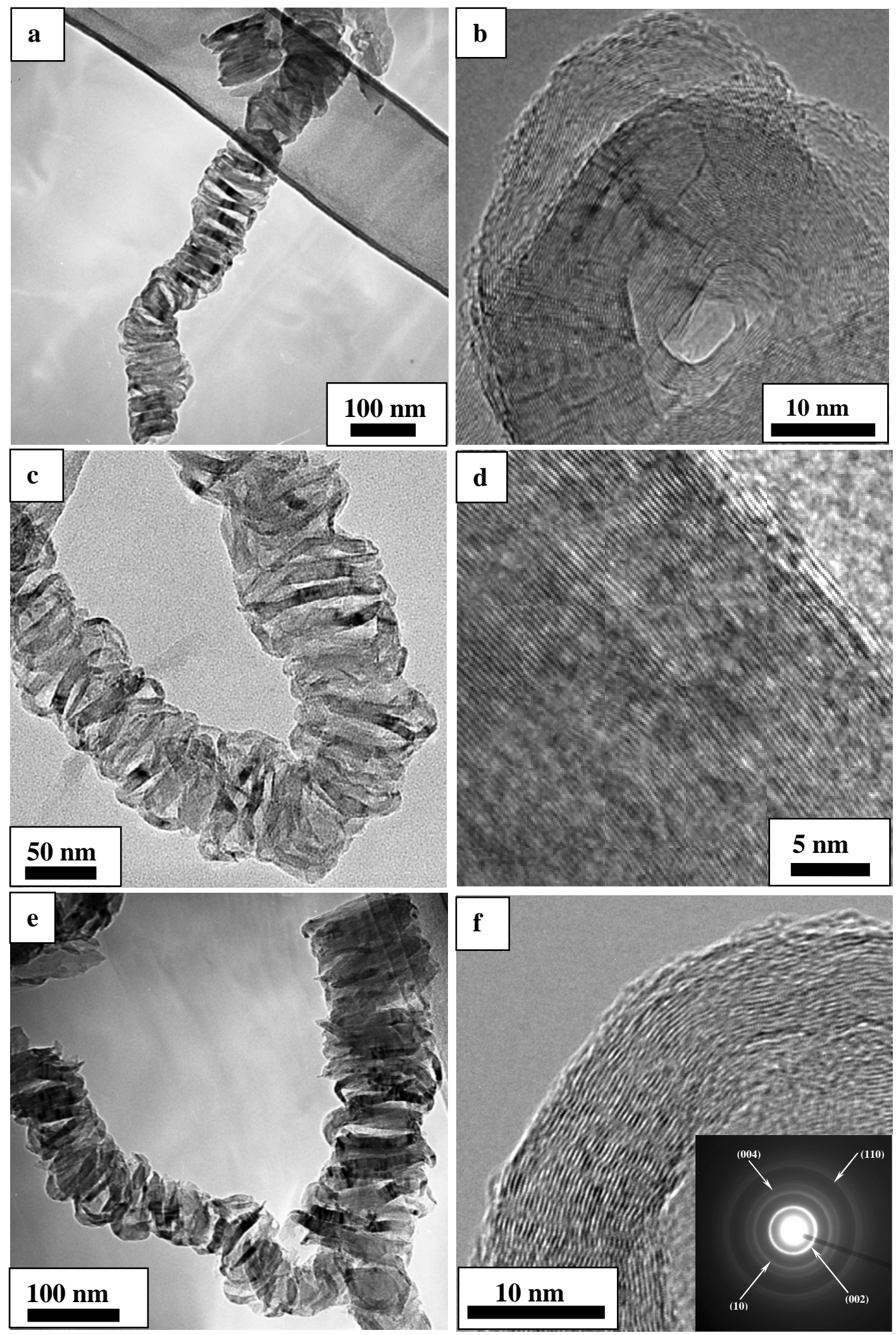

Figure 4. TEM (a, c, e) and HRTEM (b, d, f) images, and SAED patterns (inset in $f$ ) of graphitic carbon nanocoils obtained by using hydrochar materials derived from glucose $(a, b)$, sucrose $(c, d)$ and starch (e, f) as carbon precursors. 

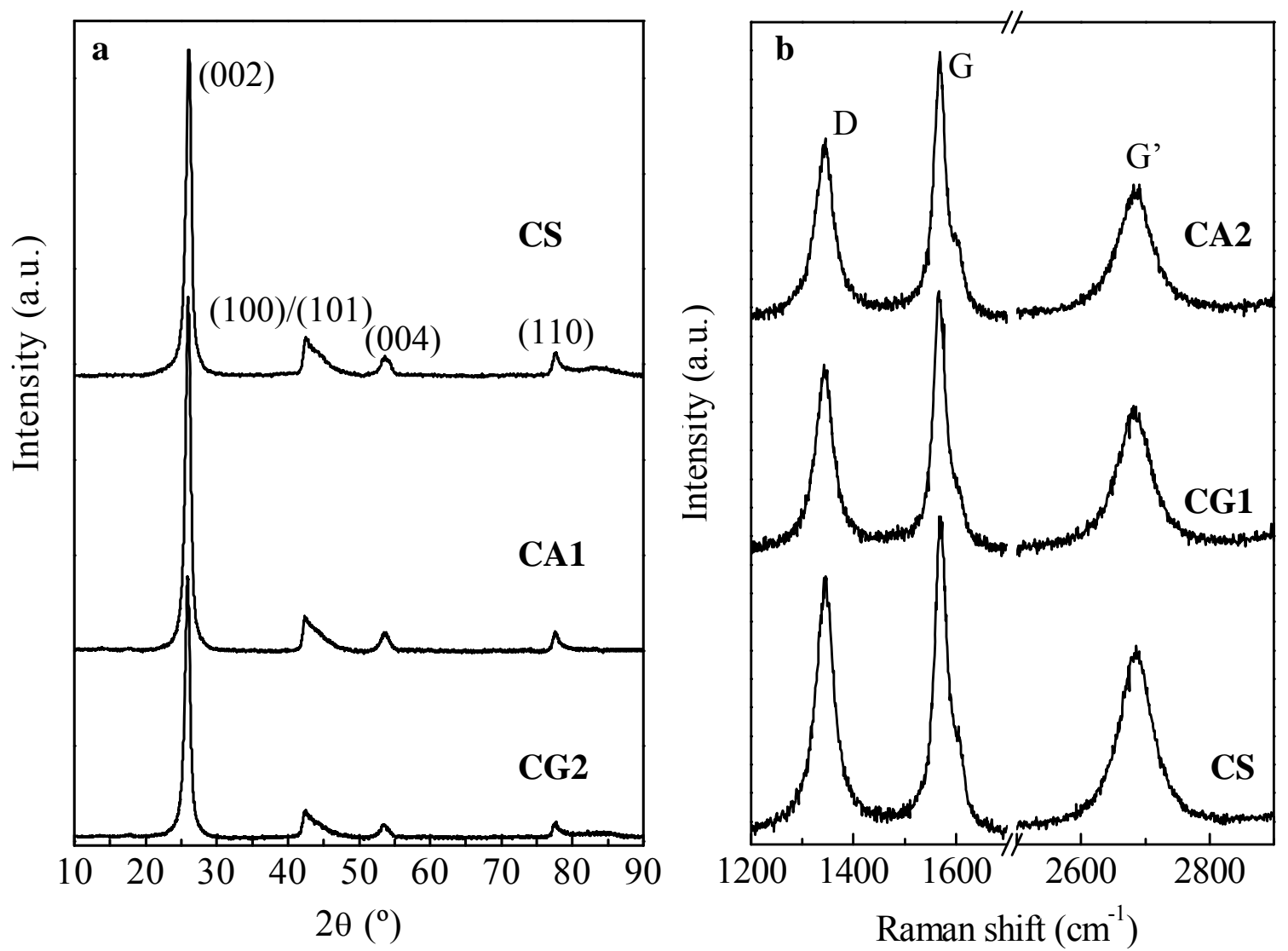

Figure 5. XRD patterns (a) and Raman spectra (b) of the graphitic carbon nanocoils. 

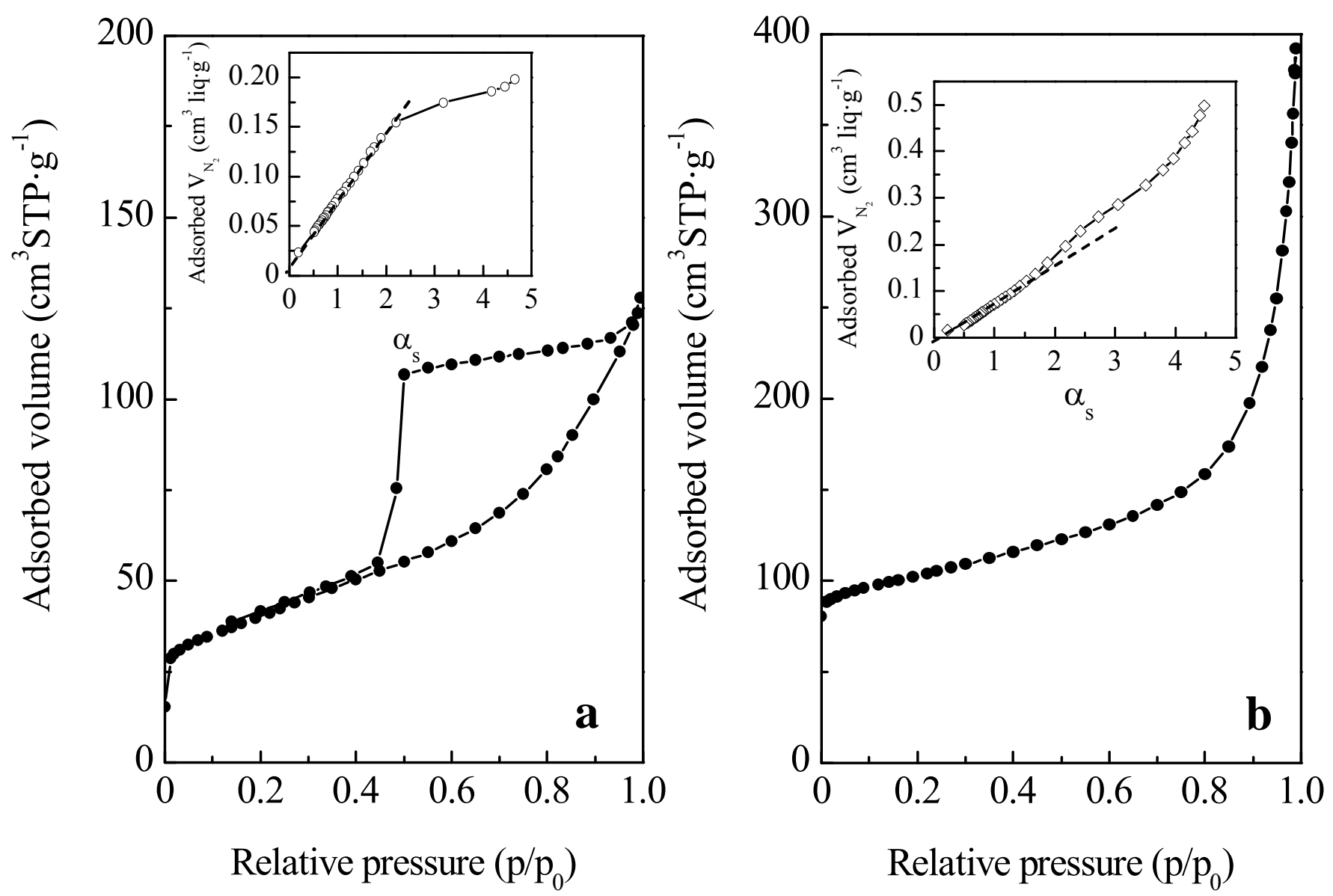

Figure 6. Typical nitrogen sorption isotherms of a graphitized carbon before (a) and after (GCNC) (b) the removal of the amorphous carbon. These graphs correspond to the samples obtained from starch. For the other precursors, the results are analogous. The insets in both figures represent the $\alpha_{\mathrm{s}}$-plot analysis applied to the adsorption branch of the $\mathrm{N}_{2}$ sorption isotherms. 